\title{
Complex secondary metabolites in plant-environment interactions and adaptation of tea plants for sustainable green food production
}

\author{
Penghui $\mathrm{Li}^{1}$, Xiao-Chun $\mathrm{Wan}^{1}$, and Jian Zhao ${ }^{1}$ \\ ${ }^{1}$ Anhui Agricultural University
}

May 5, 2020

\begin{abstract}
Tea is the second most consumed non-alcoholic beverage, only next to water. However, its production and qualities, including rich flavors and numerous health benefits, are often degraded by environmental stresses and contaminations with various agrochemicals. While most of tea quility-contributing secondary metabolites are synthesized in tea plant leaves, such as catechins, caffeine, volatiles, saponins, and theanine, primarily for defenses against biotic and abiotic stresses, few tea garden management measures have employed this tea plant innate innumity to enhance their tolerance against environmental stresses. This is partly due to the limited understanding of the biosynthesis and regulationof tea plant secondary metabolism. Given the importance of tea plant secondary metabolites for both tea flavors, health functions, and resistance against environmental stresses, study and in-depth understanding of the biosynthesis and environmental regulation of tea plant specialized metabolites are highly expected. Strategies developed from these studies would promote the production of safe and high quality teas. The review highlights relevant contexts of tea plant-environmental interaction at the secondary metabolism interfaces, particular their roles in enhancement of tea plant innate immunity and tea quality, so as to guide future research on genetic improvement of tea plants for safer food production and better human nutrition.
\end{abstract}

\section{Hosted file}

Tea secondary metabolism and environmental interaction-JZhaoR1.doc available at https: //authorea.com/users/296696/articles/432320-complex-secondary-metabolites-in-plantenvironment-interactions-and-adaptation-of-tea-plants-for-sustainable-green-foodproduction 


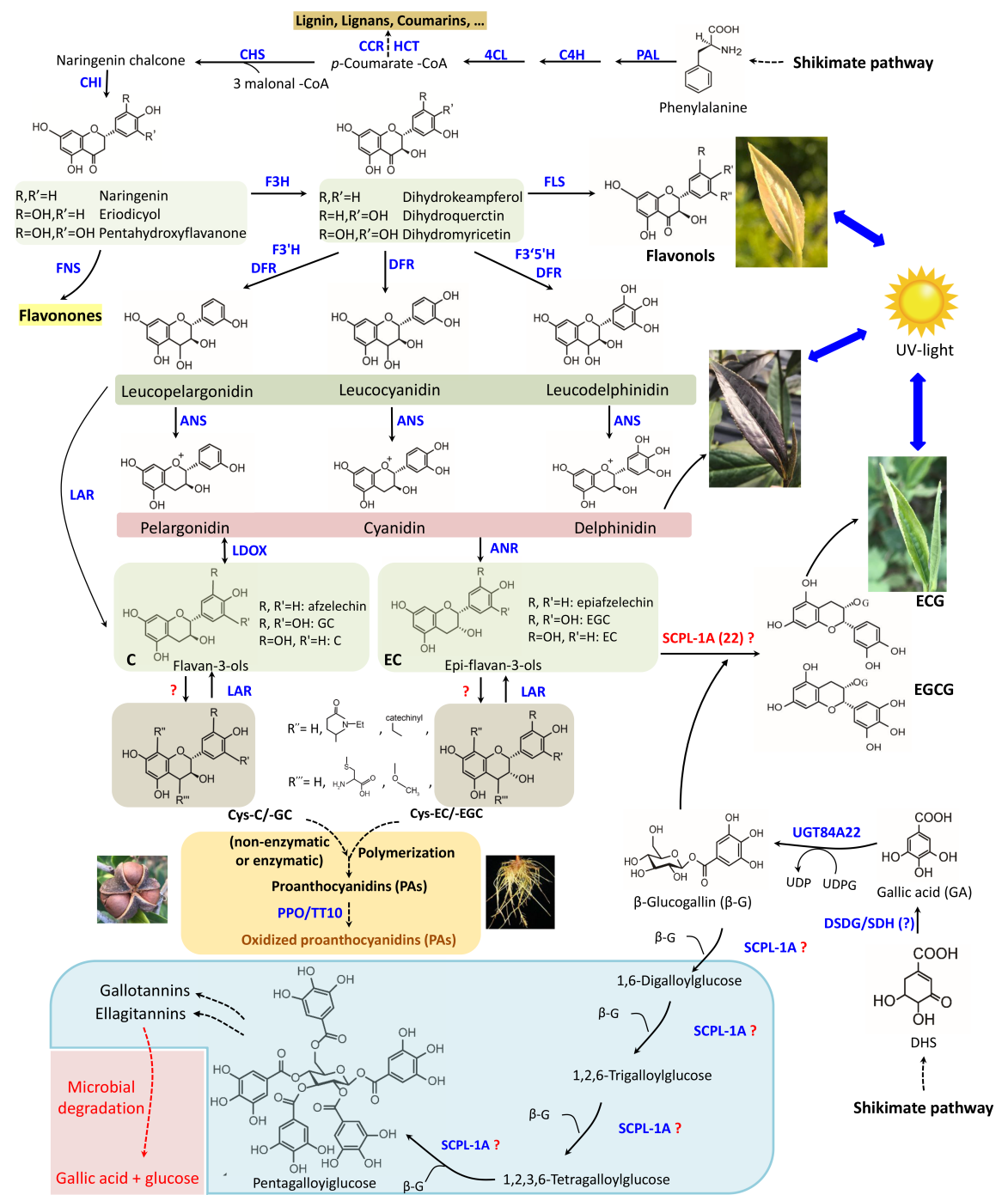



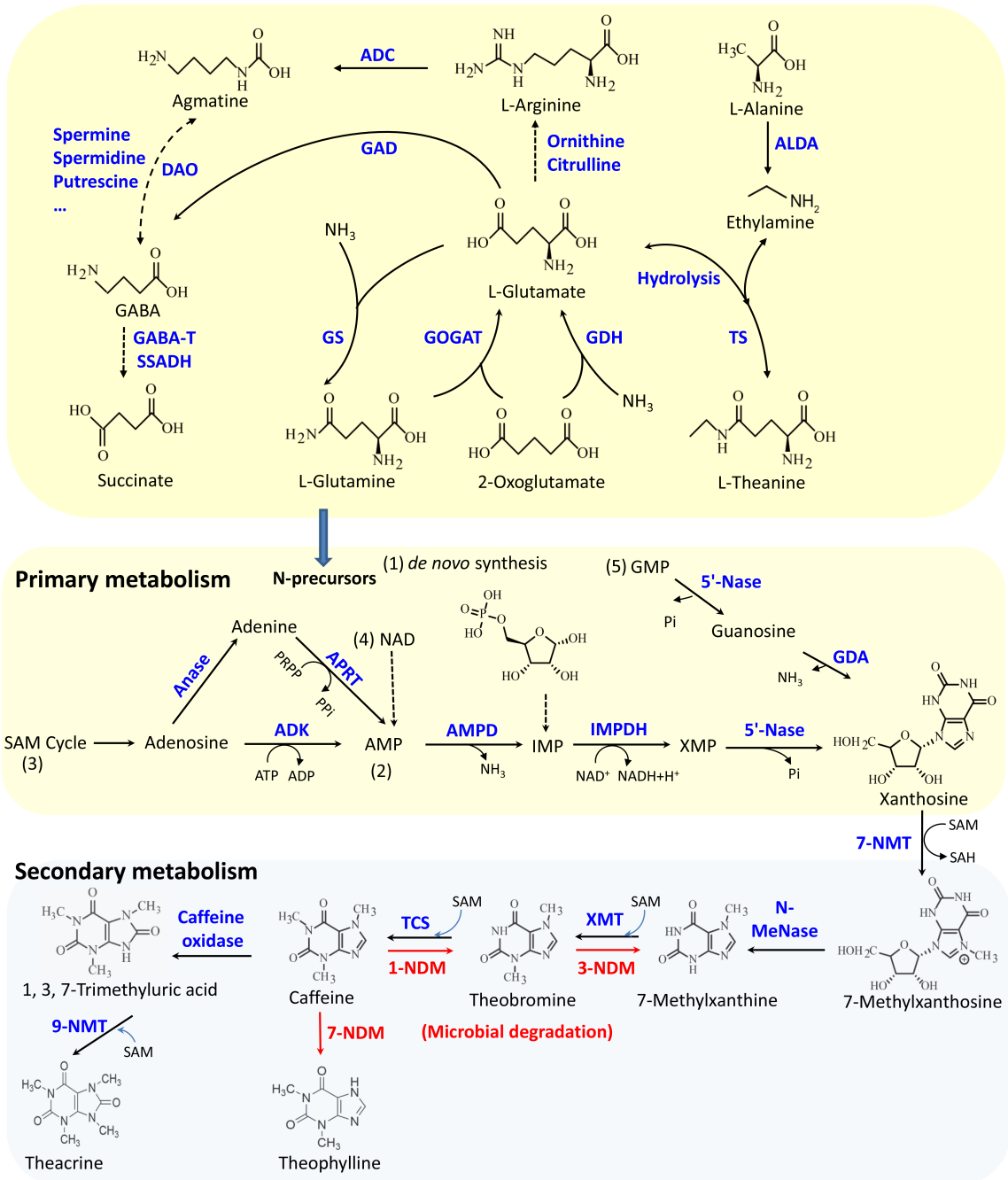

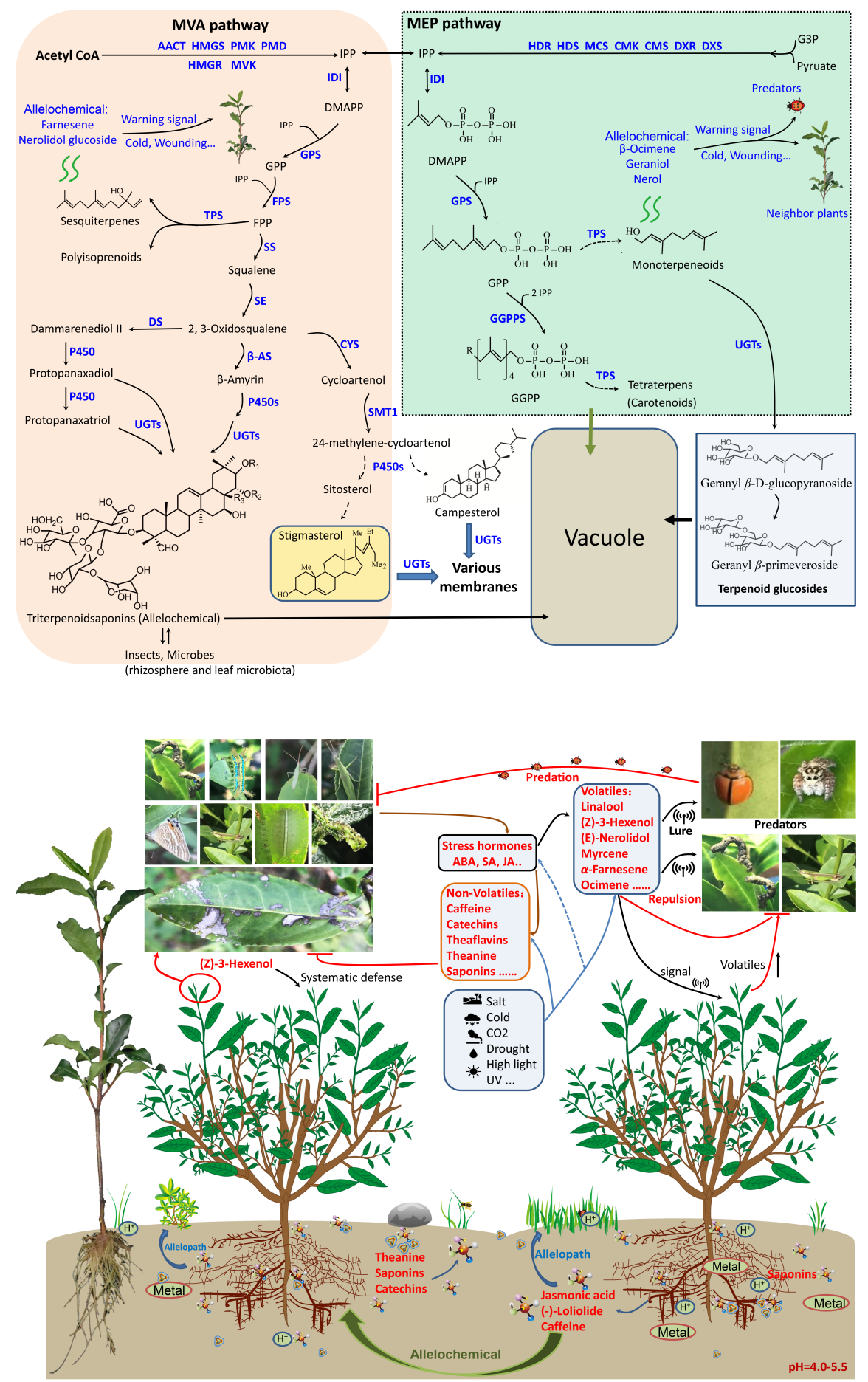

Secretion compunds (2) Germs Metal Metal ions $(4)$ Hydrogen ions 


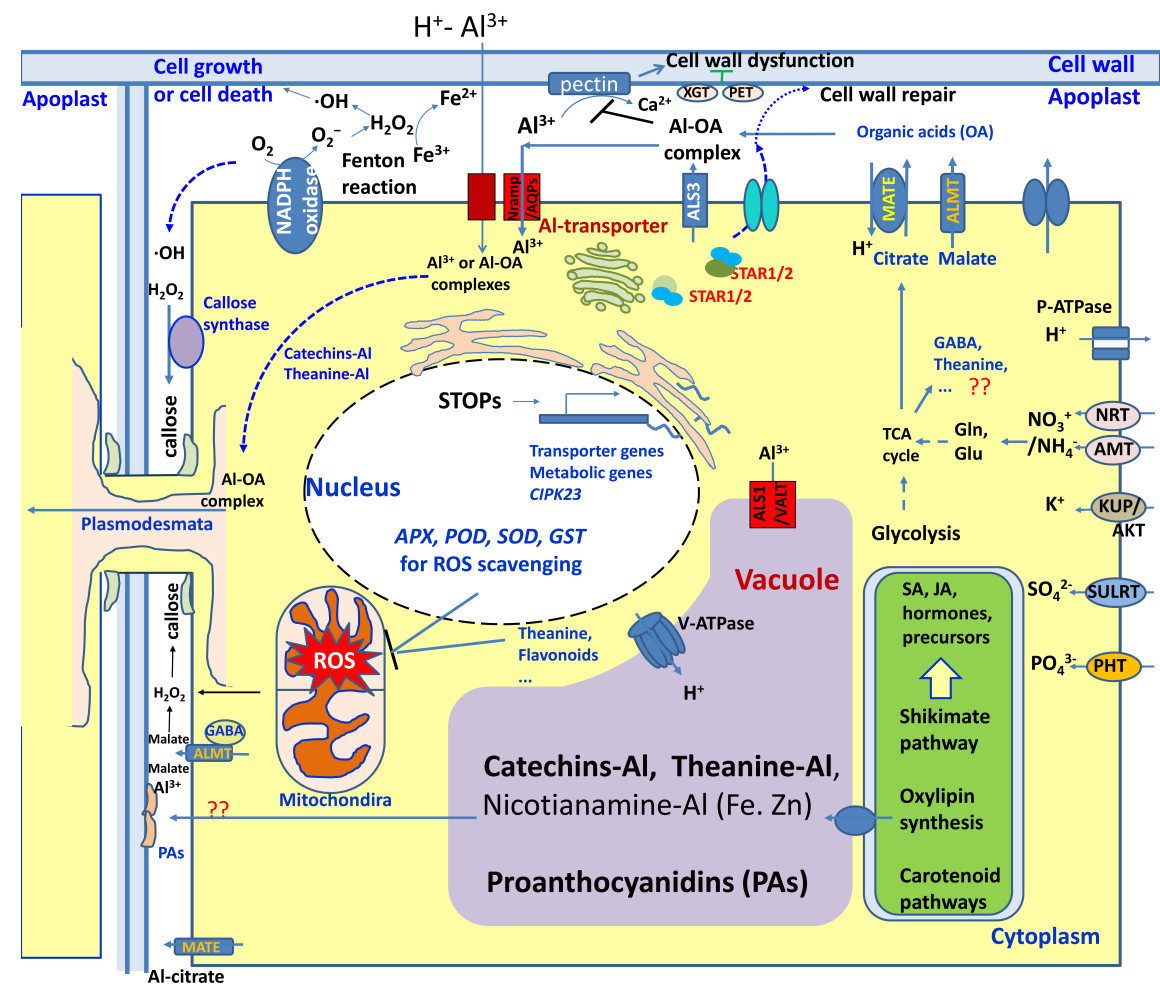

